\title{
Perancangan IT Balanced Scorecard dalam Penyusunan Strategy maps Perguruan Tinggi (Studi kasus: Institut Teknologi Telkom Purwokerto)
}

\author{
Designing an IT Balanced Scorecard in Preparing Higher Education \\ Strategy maps (Case Study: Telkom Institute of Technology Purwokerto)
}

\author{
Wahyu Adi Prabowo1* ${ }^{*}$, Yudha Saintika² \\ 1)Program Studi Informatika, Fakultas Teknologi Industri dan Informatika \\ 2)Program Studi Sistem Informasi, Fakultas Teknologi Industri dan Informatika \\ Institut Teknologi Telkom Purwokerto \\ Jl. D. I. Panjaitan No. 128, Purwokerto, Jawa Tengah 53147. Telp. (0281) 641629 \\ *email : wahyuadi@ittelkom-pwt.ac.id
}

\begin{abstract}
Histori Artikel:
Submitted:

$09 / 02 / 2018$

Accepted: $25 / 05 / 2018$

Published: $02 / 06 / 2018$
\end{abstract}

\begin{abstract}
ABSTRAK
Kebutuhan Teknologi Informasi (TI) didalam institusi pendidikan menjadi kebutuhan yang sangat mutlak di saat ini. Kebutuhan Teknologi Informasi juga menjadi peranan penting untuk meningkatkan kinerja institusi pendidikan khususnya di Institut Teknologi Telkom Purwokerto (ITTP). Peranan IT Balanced Scorecard menjadi keunggulan tersendiri demi tercapainya visi misi ITTP sebagai kampus yang sangat mengedepankan TI baik itu di dalam kinerja manajemen dan pendidikan. Keunggulan IT Balanced Scorecard salah satunya adalah mendukung IT Governance, ini sangat diperlukan institusi untuk dapat menciptakan adanya sebuah keselarasan bisnis dan teknologi informasi demi mewujudkan continuous improvement ITTP. Permasalahan di ITTP saat ini dalam hal kegiatan perencanaan kinerja TI belum mengacu atau berpedoman ke sebuah standar tertentu. Kondisi yang terjadi sekarang adalah masing-masing unit/bagian merumuskan kebutuhan mereka secara subjektif dan tanpa pertimbangan khususnya di bagian IT Support. Penelitian ini bertujuan untuk merancang IT Balanced Scorecard yang nantinya akan digunakan untuk mengukur kinerja IT ITTP. Penelitian ini dimulai dengan menganalisa visi misi dan strategi yang didasarkan dari renstra ITTP dan menganalisis SWOT IT yang ada di ITTP untuk mengetahui kondisi saat ini. Kemudian penulis menganalisis matriks TOWS untuk mengetahui strategi dan KPI terbaik untuk ITTP kedepannya. Untuk membangun sasaran strategis dan strategy maps yang tepat, penulis mengacu kepada renstra (Rencana Strategis) ITTP agar terciptanya keselarasan bisnis dan IT. Langkah selanjutnya adalah dengan memetakan KPI hasil dari analisa matriks TOWS ke dalam sasaran strategi yang sudah dibentuk, sehingga IT Balanced Scorecard dapat terbentuk. Keobjektivitasan penelitian sangat mutlak diperlukan dalam membangun IT Balanced Scorecard sehingga penelitian pada studi kasus ini dapat menghasilkan 12 sasaran strategis dan menghasilkan 20 KPI yang akan digunakan sebagai ukuran kinerja IT Balanced Scorecard.
\end{abstract}

Kata Kunci : IT Balanced Scorecard, IT Governance, SWOT, strategy maps

\footnotetext{
ABSTRACT

The need of Information Technology in educational institutions has been an absolute necessity today. Information Technology also plays an important role to improve the performance of educational institutions, especially at Institute of Technology Telkom Purwokerto (ITTP). Thus, the role of IT Balanced
} 


\section{Wahyu Adi Prabowo1*, Yudha Saintika2}

Perancangan IT Balanced Scorecard dalam Penyusunan Strategy maps Perguruan Tinggi (Studi kasus: Institut Teknologi Telkom Purwokerto)

Scorecard performs more advantages to aim the mission and vision of ITTP as an institutue that comes with great stress of IT both in management and education performance. The advantages of IT Balanced Scorecard is one of the factors to support IT Governance. Therefore, it is necessary for the institution to create a conformity of business and information technology to achieve continuous improvement of ITTP. However, ITTP has been facing problems in terms of IT performance planning activities that have not been referenced or guided to certain standard. Each unit / section now is dealing with problems where they formulate their needs subjectively and without consideration, especially when it is related to IT Supports. This research aims to design IT Balanced Scorecard which would be used to measure IT performance of ITTP. This research begins with analyzing the mission, vision and strategy based on ITTP strategic plan and analyzing the SWOT of IT in ITTP to uncover the real current conditions. Furthermore, the TOWS matrix would be anaylized to find out the best strategy and KPI to support ITTP in the future. To build the right strategic targets and strategic maps, the authors refer to the ITTP strategic plans to create business and IT alignment. The next step is to map the KPI results from the TOWS matrix analysis into the objectives of the established strategy, so that an IT Balanced Scorecard can be formed. The objectivity of research is an absolute necessity to IT Balanced Scorecard so this case-study research would produce 12 strategic objectives and $20 \mathrm{KPI}$ which would be used as a measurement of IT Balanced Scorecard performance.

Keywords: IT Balanced Scorecard, IT Governance, SWOT, strategy maps

\section{PENDAHULUAN}

Persaingan sektor pendidikan telah mempengaruhi upaya perguruan tinggi untuk meningkatkan budaya mutu kinerjanya. Budaya mutu kinerja juga telah merubah paradigma perguruan tinggi yang lama menjadi sebuah paradigma perguruan tinggi yang baru. Konsep dasar paradigma baru pendidikan tinggi terletak pada ukuran mutu yang terkait dengan empat aspek, yaitu otonomi, akuntabilitas, akreditasi, dan evaluasi. Dengan fokus pada pencapaian target kulitatif, di mana penelitian dijadikan soko guru pengembangan perguruan tinggi akademik Paradigma perguruan tinggi yang baru mengacu kepada mutu kualitas penyelenggaraan pendidikan (Indrawan, 2008).

Salah satu bentuk untuk meningkatkan mutu kualitas perguruan tinggi adalah dengan didukungnya infrastruktur teknologi dan sistem informasi. Peranan teknologi informasi saat ini telah banyak diadopsi oleh perguruan tinggi. Hal ini dipercaya bahwa dengan mengadopsi teknologi informasi akan dapat membantu perguruan tinggi dalam meningkatkan efektifitas dan efisiensi proses bisnis yang sedang berjalan.

Fungsi teknologi informasi mempunyai peranan besar untuk tercapainya sebuah Good University Governance di perguruan tinggi. Peranan IT Governance yang berkaitan dengan Good University Governance sangat diperlukan dalam menjaga kinerja perguruan tinggi serta dalam peranan tersebut perguruan tinggi diarahkan untuk menjaga kelangsungan hidup melalui pengelolaan yang didasari atas prinsipprinsip transparansi, akuntabilitas (kepada stakeholders), responsibility, independensi (dalam pengambilan keputusan), fairness (adil, penjaminan mutu dan relevansi, efektifitas dan efesiensi, serta nirlaba (Ristekdikti, 2014).

Di sisi lain, upaya dalam meningkatkan kualitas proses bisnis pendidikan tinggi harus mempunyai operasional yang efektif dan efisien. Untuk itu perlu dipelajari di level manakah kecocokan strategi yang terbaik antara strategi bisnis dan strategi TI di tingkat perguruan tinggi, dengan menganalisa, mengkaji konsep dan teknik penyelarasan yang tepat agar strategi tersebut bisa di terapkan di perguruan tinggi (Herdiansyah et al., 2014). Untuk menghadapi tantangan global, Institut Teknologi Telkom Purwokerto (ITTP) sebagai institusi pendidikan perguruan tinggi yang berbasis Information and communications technology (ICT) harus selalu berusaha untuk meningkatkan mutu kualitas kinerja perguruan tinggi termasuk kinerja strategi teknologi informasi di ITTP, serta melakukan continuous improvement di unit IT Support. Ini semua dilakukan untuk menghadapi perkembangan teknologi yang berpengaruh besar terhadap perkembangan perguruan tinggi ITTP.

Implementasi TI perlu dikelola dengan baik agar menghasilkan informasi yang berkualitas bagi pemangku kepentingan dan memberikan keunggulan bersaing bagi institusi pendidikan tinggi (Maria, 2011). Permasalahan yang terjadi dalam investasi teknologi informasi ITTP saat ini adalah dalam hal kegiatan perencanaan strategi TI belum mengacu atau berpedoman ke sebuah standar tertentu, sehingga strategi teknologi informasi ITTP masih 


\section{Wahyu Adi Prabowo1*, Yudha Saintika2}

Perancangan IT Balanced Scorecard dalam Penyusunan Strategy maps Perguruan Tinggi (Studi kasus: Institut Teknologi Telkom Purwokerto)

bersifat kondisional sehingga belum terarah dalam pemenuhan kebutuhan stakeholder.

Kondisi yang terjadi sekarang adalah masing-masing unit/bagian merumuskan kebutuhan mereka secara subjektif, khususnya di bagian IT Support. Besarnya investasi TI yang sudah dilakukan belum tergambarkan adanya sebuah peningkatan kualitas kinerja produktivitas dari perguruan tinggi ITTP. Istilah "IT productivity paradox"(Brynjolfsson, 1994; Brynjolfsson \& M. Hitt, 1998; Hwang et al, 2014; Mason et al, 2000) atau "IT Black Hole" (ISACA, 2005) merupakan gambaran yang tepat untuk hal ini, dimana investasi teknologi informasi yang telah diinvestasikan belum menggambarkan perubahan bagi produktivitas kualitas perencanaan kinerja TI perusahaan dalam mencapai tujuan bisnisnya.

Penelitian tentang IT Productivity Paradox atau IT Black Hole sebelumnya diketahui bahwa diakibatkan adanya sebuah missmeasurement atau kesalahan pengukuran. Kesalahan pengukuran ini diakibatkan oleh karena cara untuk mengukur manfaat tersebut hanya dilakukan dengan mengukur keuangan saja, tetapi masih ada manfaat TI yang bersifat intangible seperti perbaikan posisi yang kompetitif, meningkatkan hubungan dengan pelanggan dan perubahan kekuatan di dalam distribusi dan supply channels, dan lain lain (Chircu et al, 2001) sehingga antara bisnis dan teknologi informasi harus bisa dirasakan keuntungan dan manfaatnya baik itu berupa tangible dan intangible. Kondisi yang terjadi sekarang pengukuran kinerja IT Support masih di bawah kontrak manajemen (KM) Yayasan Pendidikan Telkom (YPT) yang hanya terdapat 2 indikator yang terkait dengan infrastruktur IT, yaitu, Pengembangan Sistem Informasi DAN Support Dashboard YPT.

Angka ketercapaian dari Pengembangan Sistem Informasi, menunjukkan angka ketercapaian kurang dari $100 \%$ dan angka ketercapaian Support Dashboard YPT menunjukkan angka $100 \%$. Strategi IT dari unit IT Support tidak cukup dengan hanya 2 indikator, dari hal tersebut belum ada sebuah penyelarasan antara strategi bisnis dan strategi IT secara keseluruhan. Dari banyaknya peneliti telah menyetujui bahwa kemungkinan resiko terbesar dan yang menjadi pusat perhatian dari top manajemen adalah gagal untuk menyelaraskan kebutuhan TI dengan kebutuhan bisnis yang nyata, dan gagal untuk memberikan nilai bagi bisnis. Sejak TI menjadi fokus area yang khusus bagi perguruan tinggi ITTP maka penting untuk melakukan pengelolaan TI secara efektif dan efisien sehingga nanti akan memberikan dampak bagi kinerja TI secara keseluruhan sehingga investasi terhadap TI perguruan tinggi ITTP tidak menjadi sia-sia.

Investasi TI yang terus meningkat begitu pula ketergantungan perguruan tinggi ITTP terhadap infrastruktur TI dan kinerja fungsi TI yang harus menjadi fokus para manajemen, untuk memastikan nilai yang diterima dari investasi TI dapat dikelola dengan baik dan dapat dikelola resikonya dengan baik juga. Untuk itu diperlukan sebuah pengukuran dari investasi teknologi informasi terhadap bisnis yang telah berjalan, untuk menentukan bahwa investasi tersebut sudah sejalan dengan bisnisnya. IT Balanced Scorecard merupakan salah satu metode sebagai pengukuran kinerja TI. IT Balanced Scorecard dibentuk dari tujuan bisnis perusahaan lalu diturunkan ke tujuan TI dan di akhir metode tersebut adalah membentuk sebuah indikator-indikator yang akan digunakan untuk mengukur kinerja TI perguruan tinggi ITTP, sehingga akan terbentuk sekumpulan indikator TI di setiap perspektif dalam IT Balanced Scorecard yaitu Perspektif Kontribusi perusahaan (Corporate Contribution), Perspektif Orientasi Pengguna (User Orientation), Perspektif Penyempurnaan Operasional (Operational Execellence), dan Perspektif Orientasi Masa Depan (Future / Innovation).

Fokus tujuan dari penelitian ini adalah untuk merancang IT Balanced Scorecard untuk mengukur kinerja TI di perguruan tinggi ITTP. Pengukuran kinerja TI perlu dilakukan guna untuk mengetahui sejauh mana peranan TI dalam menciptakan sebuah hubungan antara kinerja TI dengan strategi TI, yang seharusnya mendukung strategi bisnis (Lee, Chen, \& Chang, 2008).

\section{METODOLOGI PENELITIAN}

Proses perancangan IT Balanced Scorecard dibutuhkan data sekunder yang dikumpulkan dari unit IT Support ITTP. Selain itu penulis juga menggunakan data sekunder yang terdiri dari rencana strategis ITTP 2018-2022.

Alur metodologi penelitian seperti terlihat pada Gambar 1. Penelitian dilakukan dengan menganalisis visi dan misi ITTP yang kemudian dikembangkan ke dalam pertanyaan di masing-masing perspektif IT Balanced Scorecard, pertanyaan tersebut nanti akan diajukan ke dalam wawancara dengan manajemen dan unitunit kerja yang berada di bawah kendali ITTP terkait dengan Teknologi Informasi. Pertanyaan disusun untuk menemukan kekuatan (strengths), 


\section{Wahyu Adi Prabowo1*, Yudha Saintika2}

Perancangan IT Balanced Scorecard dalam Penyusunan Strategy maps Perguruan Tinggi (Studi kasus: Institut Teknologi Telkom Purwokerto)

kelemahan (weaknesses), peluang (opportunities), dan ancaman (threats) (SWOT) terkait dengan Teknologi Informasi yang ada di ITTP. Yang nantinya dari pertanyaan tersebut hasilnya akan dihubungkan kedalam dimensi dari masing masing perspektif IT Balanced Scorecard. Hasil dari setiap perspektif akan dibentuk sebuah ukuran dan sasaran strategis yang relevan terhadap kondisi TI yang ada di ITTP yang berkaitan dengan renstra ITTP.

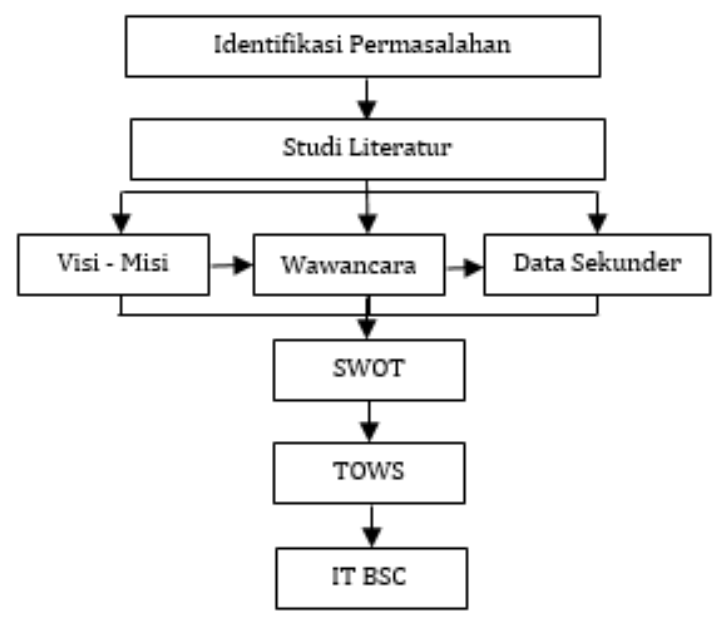

Gambar 1. Metodologi Penelitian

\section{HASIL DAN PEMBAHASAN}

\section{A. Analisis SWOT}

Sebagai salah satu perguruan tinggi yang fokus di bidang ICT, ITTP saat ini memiliki total mahasiswa kurang lebih sejumlah 1400 mahasiswa. Dengan lingkup mahasiswa yang cukup besar tersebut, ITTP memiliki Struktur Organisasi Tata Kelola (SOTK) yang terdiri dari tiga bidang utama. Di dalam masing-masing bidang tersebut terdapat unit-unit yang terlibat sebagai responden penelitian ini yaitu Bidang I yang terdiri dari unit akademik, unit prodi dan fakultas, dan unit LPPM. Kemudian Bidang II terdiri dari unit SDM, logistik, IT Support, keuangan, dan sekretariat manajemen. Sedangkan Bidang III yang terdiri dari unit pemasaran dan kemahasiswaan.

Jika dilihat dari Gambar 2, rincian SOTK institusi tersebut, maka posisi pengelola SI/TI berada pada unit IT Support yang saat ini terdiri dari urusan layanan dan operasional dan urusan infrastruktur dan pengembangan konten.

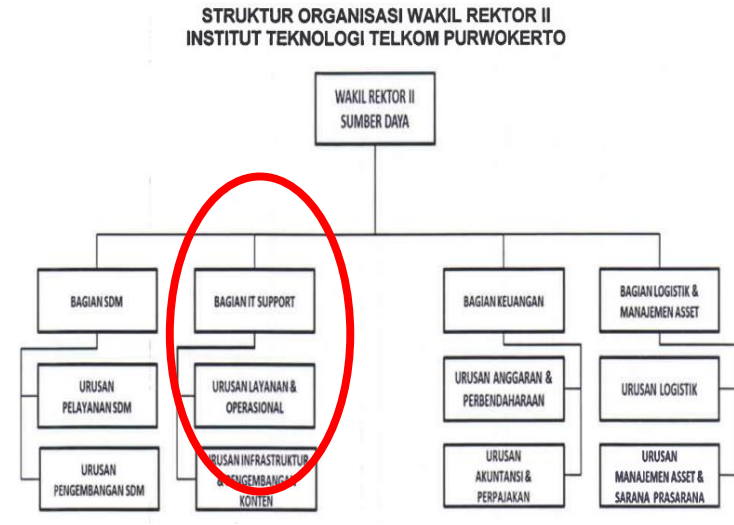

Gambar 2. Struktur Organisasi Pengelola SI/TI

(Sumber : http://ittelkom-pwt.ac.id/aboutus/organisasi/)

Penelitian ini dimulai dengan menganalisis visi dan misi yang terdapat dalam rencana strategis ITTP tahun 2018-2022 untuk memberikan informasi mengenai detail gambaran internal organisasi, yang terdiri atas visi, misi, tujuan strategis dan struktur organisasi.

Visi : "Menjadi perguruan tinggi yang unggul dalam pengembangan ilmu pengetahuan berbasis teknologi informasi dan membentuk insan yang berkarakter di Indonesia."

Adapun misi ITTP berdasarkan dokumen Statuta ITTP adalah sebagai berikut:

1. Menyelenggarakan dan mengembangkan pendidikan berbasis teknologi telematika yang berkualitas dan pembentukan karakter yang unggul

2. Mengembangkan riset dan menyebarluaskan sains, teknologi dan teknik yang terkini

3. Menerapkan dan memanfaatkan sains, teknologi dan teknik bagi kemaslahatan masyarakat

4. Mengembangkan tata kelola berbasis best practices dan menjalin kerjasama yang berkualitas dengan institusi pendidikan, pemerintah dan dunia industri di dalam dan luar negeri

Sedangkan tujuan strategis yang harus dicapai adalah "peningkatan tata kelola lembaga dalam rangka adanya perubahan yang mampu mewujudkan academic excellence".

Selain berpedoman kepada rencana strategis, data-data terkait daftar sistem informasi dan infrastruktur juga dikumpulkan untuk kemudian dianalisis. Daftar sistem informasi yang ada di ITTP seperti terlihat pada Tabel 1. 


\section{Wahyu Adi Prabowo1*, Yudha Saintika2}

Perancangan IT Balanced Scorecard dalam Penyusunan Strategy maps Perguruan Tinggi (Studi kasus: Institut Teknologi Telkom Purwokerto)

Tabel 1. Daftar Sistem Informasi

\begin{tabular}{|c|c|}
\hline No & Sistem Informasi \\
\hline \multirow[t]{2}{*}{1} & Sistem Informasi Akademik: Digital \\
\hline & Information System (Dions) \\
\hline 2 & e-learning \\
\hline 3 & Sistem Informasi Perpustakaan \\
\hline 4 & E-journal \\
\hline 5 & $\begin{array}{l}\text { Sistem Aplikasi Pelaporan Keuangan dari } \\
\text { IT Telkom ke Yayasan (simonal) }\end{array}$ \\
\hline 6 & Website official ittelkom.ac.id \\
\hline 7 & Blog dosen, mahasiswa, staff, UKM \\
\hline 8 & $\begin{array}{l}\text { Sistem Informasi } \\
\text { (biani.st3telkom.ac.id) }\end{array}$ \\
\hline 9 & Aplikasi Memo online \\
\hline 10 & Aplikasi Nomor surat kesekretariatan \\
\hline
\end{tabular}

Kemudian untuk pengelolaan infrastruktur di ITTP khususnya untuk jaringan internet yang ada saat ini dapat dilihat pada Gambar 3 berikut ini:

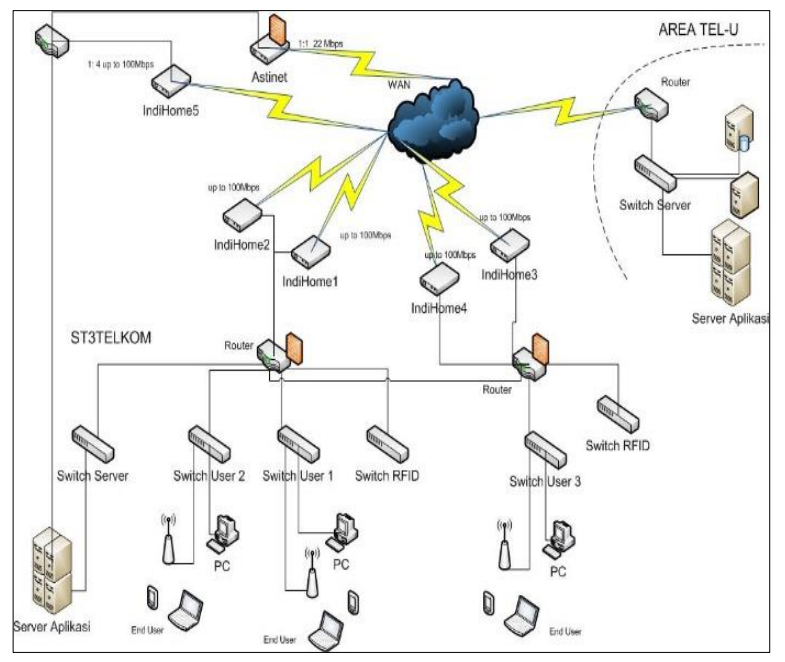

Gambar 3. Topologi Jaringan ITTP

(Sumber : ST3 Telkom Purwokerto Information Technology Blue Print)
Berdasarkan Gambar 3 Topologi diatas, maka dapat dijelaskan sebagai berikut:

- Server Fisik di area Telkom University terdiri atas 3 unit server (hibah Yayasan) yang digunakan untuk aplikasi dions dan database CDN.

- Server Fisik lokal yang ada di ITTP, dimana terbagi menjadi 2 unit lama dan 1 unit baru.

- $\quad$ Server Virtual (Virtual Private Server) yang digunakan untuk dions, blog, ejournal, dan web site official ITTP.

- $\quad$ Bandwidth yang tersedia di ITT Purwokerto saat ini adalah up to 522 Mbps dengan jumlah user kurang lebih sejumlah 1500.

Dari data-data tersebut peneliti lalu melanjutkan dengan melakukan wawancara dan observasi terkait dengan lingkungan eksternal maupun internal TI yang ada di ITTP. Dari hasil data-data wawancara dihasilkan analisis SWOT (Strength, Weakness, Opportunity, Thread) Teknologi Informasi di ITTP. Wawancara dilakukan dengan seluruh unit terkait yang ada di lingkungan ITTP termasuk manajemen untuk memperoleh data mengenai keadaan internal TI secara detail. Rincian analisis hasil pemetaan SWOT dapat dilihat pada Tabel 2 berikut ini : 
Tabel 2. Daftar SWOT internal TI ITTP

\begin{tabular}{|c|c|c|}
\hline Strength (S) & & Weaknesses (W) \\
\hline $\begin{array}{l}\text { 1.Sudah ada } \\
\text { bagian/biro khusus } \\
\text { yang menangani } \\
\text { teknologi informasi } \\
\text { yaitu IT Support } \\
\text { 2. Terdapat 6 } \\
\text { Prosedur Standar } \\
\text { Mutu (PSM) yang } \\
\text { terdapat di unit IT } \\
\text { Support. PSM } \\
\text { tersebut mengatur } \\
\text { tentang proses } \\
\text { pengecekkan } \\
\text { Hardware dan } \\
\text { Jaringan. Pengolahan } \\
\text { Data Sistem } \\
\text { Informasi, } \\
\text { Permintaan Aplikasi, } \\
\text { Penanganan } \\
\text { Komplain, } \\
\text { Permintaan } \\
\text { username dan } \\
\text { password, dan } \\
\text { Update atau revisi } \\
\text { nilai. }\end{array}$ & $\begin{array}{l}\text { 1. IT Telkom Purwol } \\
\text { Telkom Purwokerto } \\
\text { berada di Telkom un } \\
\text { - Belum adanya fasil } \\
\text { - Belum adanya top } \\
\text { 2. Bandwidth yang t } \\
\text { dengan jumlah user } \\
\text { dimana setiap acces } \\
\text { 3. Belum memiliki si } \\
\text { digunakan. } \\
\text { - Belum ada standar } \\
\text { informasi } \\
\text { 4. Aplikasi belum te } \\
\text { 5. Beberapa aplikasi } \\
\text { 6. Aplikasi yang ada } \\
\text { 7.Dalam struktur or } \\
\text { yang menangani strc } \\
\text {-Jumlah staff non do } \\
\text { orang } \\
\text { 8.Kegiatan pelatihan } \\
\text { Sifatnya masih incid } \\
\text { 9.Belum adanya pen } \\
\text { jelas. } \\
\text { 10. Belum adanya Sc } \\
\text { 11. Belum adanya do }\end{array}$ & $\begin{array}{l}\text { erto memiliki } 7 \text { server yang digunakan untuk IS/IT IT } \\
\text { Namun server-server tersebut masih tersebar, ada yang } \\
\text { versity dan ada juga yang berada di ITTP } \\
\text { tas DC dan DRC untuk data center } \\
\text { ogi data center yang mengacu ke suatu standar } \\
\text { rsedia di ITT Purwokerto saat ini adalah up to } 522 \text { Mbps } \\
\text { 1800. Namun, jumlah access point hanya berjumlah } 28 \\
\text { point hanya dapat menampung user sebanyak } 20 . \\
\text { tem recovery dan backup untuk aplikasi - aplikasi yang } \\
\text { kebijakan yang mengatur tentang keamanan data dan } \\
\text { ntegrasi } \\
\text { jang terdapat di ITTP masih ada yang bersifat support } \\
\text { belum bersifat multi platform. } \\
\text { anisasi internal IT Support belum ada divisi tersendiri } \\
\text { egi dan perencanaan IS/IT } \\
\text { en yang berada di unit IT Support hanya berjumlah } 2 \\
\text { pengembangan kompetensi karyawan belum terencana. } \\
\text { ntal. } \\
\text { ukuran kinerja karyawan TI secara } \\
\text { P yang mengatur tentang pembuatan master plan TI } \\
\text { kumentasi terkait system informasi (SRS atu FSD) }\end{array}$ \\
\hline \multicolumn{2}{|c|}{ Opportunities (0) } & Threats (T) \\
\hline \multicolumn{2}{|c|}{$\begin{array}{l}\text { 1. Diharapkan adanya sistem informasi } \\
\text { yang mampu mengelola kegiatan penelitian } \\
\text { dan pengiriman hasil penelitian } \\
\text { 2. Diharapkan adanya sistem informasi } \\
\text { yang mampu menyajikan informasi } \\
\text { mengenai profil perguruan tinggi dan } \\
\text { pencarian beasiswa ataupun informasi } \\
\text { ekonomi lainnya seperti donator/sponsor } \\
\text { 3. Diharapkan adanya sistem informasi } \\
\text { yang mampu menyajikan informasi ragam } \\
\text { sosial-budaya dalam kehidupan kampus } \\
\text { melalui kegiatan kemahasiswaan }\end{array}$} & $\begin{array}{l}\text { 1. Pelaporan yang disajjikan dari sistem tidak sinkron } \\
\text { dengan system EPSBED pusat } \\
\text { 2. Sistem informasi masih bersifat silo sehingga sistem } \\
\text { pelaporan terkait akreditasi belum terintegrasi. } \\
\text { 3. Keputusan-keputusan strategis SI/TI diambil secara } \\
\text { terfragmentasi oleh unit SISFO dan/atau tiap bidang } \\
\text { tertentu. }\end{array}$ \\
\hline
\end{tabular}




\section{Wahyu Adi Prabowo1*, Yudha Saintika2}

Perancangan IT Balanced Scorecard dalam Penyusunan Strategy maps Perguruan Tinggi (Studi kasus: Institut Teknologi Telkom Purwokerto)

\section{B. Matriks TOWS ITTP}

Setelah terbentuk hasil dari analisa SWOT maka selanjutnya adalah membentuk matriks TOWS untuk membentuk Key Performance Indicator (KPI) sebagai dasar pengambilan keputusan dan untuk menentukan sasaran strategi ITTP. Sasaran strategi TI dari ITTP mengacu kepada renstra ITTP tahun 2017-2022, renstra diperlukan agar dapat terbentuknya penyelarasan antara strategi bisnis ITTP dengan strategi TI ITTP. Matriks TOWS dapat dilihat pada Tabel 3.

Tabel 3. Matriks TOWS

\begin{tabular}{|c|c|}
\hline Strategi SO & Strategi WO \\
\hline $\begin{array}{l}\text { 1. Mengembangkan sistem informasi untuk pengelolaan } \\
\text { penelitian dan pengembangan ilmu baik untuk dosen dan } \\
\text { mahasiswa }\end{array}$ & $\begin{array}{l}\text { 1. Meningkatkan kapasitas bandwith untuk } \\
\text { kelancaran implementasi sistem informasi }\end{array}$ \\
\hline $\begin{array}{l}\text { 2. Mengembangkan sistem informasi untuk mengelola } \\
\text { kegiatan pemasaran ITTP }\end{array}$ & $\begin{array}{l}\text { 2. Pembangunan data center dan DRC lokal di } \\
\text { ITTP }\end{array}$ \\
\hline $\begin{array}{l}\text { 3. Preventive update informasi mengenai beasiswa bagi } \\
\text { mahasiswa dan dosen di sistem informasi ITTP }\end{array}$ & $\begin{array}{l}\text { 3. Membuat bagian khusus perencanaan pada } \\
\text { unit IT Support }\end{array}$ \\
\hline $\begin{array}{l}\text { 4. Meningkatkan kualitas sarana dan prasarana IT di } \\
\text { lingkungan ITTP }\end{array}$ & $\begin{array}{l}\text { 4. Membuat perencanaan terkait dengan } \\
\text { pelatihan/pengembangan kompetensi } \\
\text { karyawan }\end{array}$ \\
\hline \multirow[t]{3}{*}{ 5. Mengembangkan sistem informasi kegiatan mahasiswa } & $\begin{array}{l}\text { 5. Membuat dokumen SRS atau FSD untuk } \\
\text { setiap sistem informasi yang dikelola oleh IT } \\
\text { Support }\end{array}$ \\
\hline & $\begin{array}{l}\text { 6. Membuat arsitektur integrasi dan platform } \\
\text { sistem informasi }\end{array}$ \\
\hline & $\begin{array}{l}\text { 7. Membuat standarisasi arsitektur TI } \\
\text { menggunakan enterprise architecture }\end{array}$ \\
\hline Strategi ST & Strategi WT \\
\hline $\begin{array}{l}\text { 1. Mengembangkan middle ware supaya sistem pelaporan } \\
\text { sinkron dengan EPSBED pusat }\end{array}$ & $\begin{array}{l}\text { 1. Membuat arsitektur integrasi dan platform } \\
\text { sistem informasi }\end{array}$ \\
\hline $\begin{array}{l}\text { 2. Mengembangkan sistem informasi yang memadai antar } \\
\text { unit dan saling terintegrasi (sehingga proses bisnis lebih } \\
\text { efisien, efektif, dan produktif, bahkan dapat memperoleh } \\
\text { keunggulan kompetitif, tanpa harus menurunkan kualitas } \\
\text { produk/jasa dan layanan customer.) }\end{array}$ & $\begin{array}{l}\text { 2. Membuat standarisasi arsitektur TI } \\
\text { menggunakan enterprise architecture }\end{array}$ \\
\hline $\begin{array}{l}\text { 3. Melakukan sosialisasi sistem yang telah di rancang oleh } \\
\text { unit IT Support }\end{array}$ & $\begin{array}{l}\text { 3. Membuat dokumentasi terkait dengan } \\
\text { aplikasi sistem informasi yang ada di ITTP } \\
\text { (Functional Specification / Requirement } \\
\text { Document (FSD / FRD) }\end{array}$ \\
\hline $\begin{array}{l}\text { 4. Penguatan aspek kelembagaan dengan merealisasikan } \\
\text { komite TI untuk pengambilan keputusan yang sifatnya } \\
\text { strategis }\end{array}$ & \\
\hline
\end{tabular}

\section{Strategy maps}

Langkah berikutnya adalah melakukan proses pemetaan terhadap sasaran-sasaran strategis ke dalam tiap-tiap wilayah perspektif IT Balanced Scorecard, yang nantinya akan membentuk sebuah strategy maps TI ITTP. Pengelompokkan sasaran strategis ini berdasarkan hasil dari Focus Group Discussion (FGD) dan in-depth interview dengan manajemen kerja terkait dengan kontribusi TI ITTP. Tujuan dari FGD ini adalah mengkonfirmasikan hasil dari KPI yang didapatkan ke manajemen agar bisa diusulkan sebagai rekomendasi indikator kinerja berdasarkan IT Balanced Scorecard.

Strategy maps ini dibangun dengan melihat kondisi TI ITTP sebagai "as-is condition" institusi yang diterjemahkan kedalam hubungan sebab akibat (cause-and-effect relationship) yang 


\section{Wahyu Adi Prabowo1*, Yudha Saintika2}

Perancangan IT Balanced Scorecard dalam Penyusunan Strategy maps Perguruan Tinggi (Studi kasus: Institut Teknologi Telkom Purwokerto)

dapat menggambarkan kondisi TI ITTP. Hasil dari FGD yang dapat disimpulkan dapat dilihat pada Gambar 5.

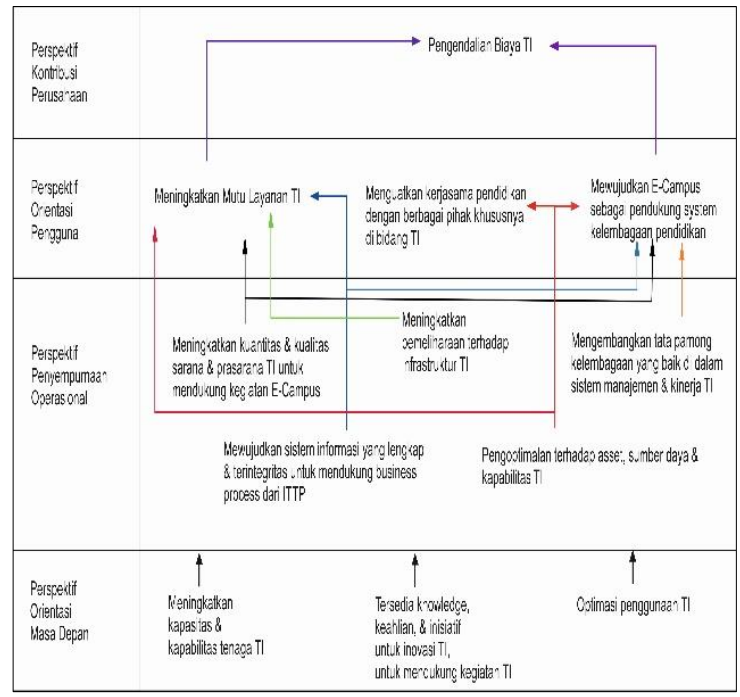

Gambar 5. Hasil FGD Strategy maps ITTP
Setelah strategy maps terbentuk maka langkah terakhir adalah memetakan sasaran strategis dengan KPI yang sudah dihasilkan dari FGD sebelumnya. Dari hasil FGD tersebut menghasilkan beberapa strategi ITTP yang selanjutnya akan dijadikan Key Performance Indicator (KPI). Selanjutnya KPI tersebut dipetakan kedalam sasaran strategi dari renstra ITTP 2017-2022 yang terkait dengan strategi ITTP agar terciptanya keselarasan bisnis dan TI. Peneliti dalam hal ini melakukan Focus Group Discussion (FGD) dengan para manajemen untuk memetakan KPI secara objektif sesuai dengan kepentingan kebutuhan TI ITTP. Gambaran dari manajemen sangat membantu penulis agar mendapatkan penjelasaan krusial yang terjadi sekarang dan 5 tahun ke depan sesuai dengan rencana strategis $\mathrm{TI}$, yang nantinya akan terbentuk sesuai dengan perspektif dari IT Balanced Scorecard. Sasaran strategi ITTP dan KPI IT Balanced Scorecard dapat dilihat pada Tabel 4.

\section{Perancangan IT Balanced Scorecard ITTP}

Tabel 4. Sasaran Strategis dan KPI

\begin{tabular}{|c|c|c|}
\hline Perspektif & Sasaran Strategic & Key Performance Indikator \\
\hline $\begin{array}{l}\text { Perspektif } \\
\text { Kontribusi } \\
\text { perusahaan } \\
\text { (Corporate } \\
\text { Contribution) }\end{array}$ & $\begin{array}{l}\text { 1. Pengendalian Biaya TI } \\
\text { (mengembangkan perencanaan } \\
\text { pendanaan ITTP secara komprehensif } \\
\text { yang dasarnya dapat diambil dari hasil } \\
\text { monitoring dan evaluasi secara } \\
\text { berkelanjutan). }\end{array}$ & Jumlah Realisasi Anggaran Biaya TI \\
\hline \multirow{8}{*}{$\begin{array}{l}\text { Perspektif } \\
\text { Orientasi } \\
\text { Pengguna (User } \\
\text { Orientation) }\end{array}$} & \multirow{4}{*}{ 1. Meningkatkan mutu layanan TI } & $\begin{array}{l}\text { Persentase capaian pembangunan data } \\
\text { center dan DRC lokal di ITTP }\end{array}$ \\
\hline & & $\begin{array}{l}\text { Pembangunan arsitektur integrasi dan } \\
\text { platform sistem informasi }\end{array}$ \\
\hline & & $\begin{array}{l}\text { Pembuatan standarisasi arsitektur TI } \\
\text { menggunakan enterprise architecture }\end{array}$ \\
\hline & & $\begin{array}{l}\text { Jumlah keluhan user yang diakibatkan bugs } \\
\text { system maupun kegiatan maintenance } \\
\text { jaringan komputer }\end{array}$ \\
\hline & $\begin{array}{l}\text { 2. Menguatkan kerjasama pendidikan } \\
\text { dengan berbagai pihak khususnya di } \\
\text { bidang IT }\end{array}$ & $\begin{array}{l}\text { Jumlah informasi beasiswa bagi mahasiswa } \\
\text { dan dosen di ITTP }\end{array}$ \\
\hline & \multirow{3}{*}{$\begin{array}{l}\text { 3. Mewujudkan E-Campus sebagai } \\
\text { pendukung sistem kelembagaan } \\
\text { pendidikan }\end{array}$} & $\begin{array}{l}\text { Pengembangan middle ware supaya sistem } \\
\text { pelaporan sinkron dengan EPSBED pusat }\end{array}$ \\
\hline & & $\begin{array}{l}\text { Pengembangan sistem informasi untuk } \\
\text { mengelola kegiatan pemasaran ITTP }\end{array}$ \\
\hline & & $\begin{array}{l}\text { Pengembangan sistem informasi kegiatan } \\
\text { mahasiswa }\end{array}$ \\
\hline $\begin{array}{l}\text { Perspektif } \\
\text { Penyempurnaan } \\
\text { Operasional }\end{array}$ & $\begin{array}{l}\text { 1. Meningkatkan kuantitas dan } \\
\text { kualitas sarana dan prasarana IT } \\
\text { untuk mendukung kegiatan E-Campus }\end{array}$ & $\begin{array}{l}\text { Jumlah sarana dan prasarana IT di } \\
\text { lingkungan ITTP }\end{array}$ \\
\hline
\end{tabular}




\section{Wahyu Adi Prabowo1*, Yudha Saintika2}

Perancangan IT Balanced Scorecard dalam Penyusunan Strategy maps Perguruan Tinggi (Studi kasus: Institut Teknologi Telkom Purwokerto)

\begin{tabular}{|c|c|c|}
\hline \multirow[t]{7}{*}{$\begin{array}{l}\text { (Operational } \\
\text { Execellence) }\end{array}$} & $\begin{array}{l}\text { 2. Meningkatkan pemeliharaan } \\
\text { terhadap infrastruktur IT }\end{array}$ & $\begin{array}{l}\text { Peningkatan kapasitas bandwith untuk } \\
\text { kelancaran implementasi sistem informasi }\end{array}$ \\
\hline & $\begin{array}{l}\text { 3. Mengembangkan tata pamong } \\
\text { kelembagaan yang baik di dalam } \\
\text { sistem manajemen dan kinerja IT }\end{array}$ & $\begin{array}{l}\text { Pelaksanaan pembuatan komite TI untuk } \\
\text { pengambilan keputusan yang sifatnya } \\
\text { strategis }\end{array}$ \\
\hline & \multirow{3}{*}{$\begin{array}{l}\text { 4. Mewujudkan sistem informasi yang } \\
\text { lengkap dan terintegrasi untuk } \\
\text { mendukung business process dari } \\
\text { ITTP }\end{array}$} & $\begin{array}{l}\text { Jumlah dokumentasi terkait dengan aplikasi } \\
\text { sistem informasi yang ada di ITTP } \\
\text { (Functional Specification / Requirement } \\
\text { Document (FSD / FRD) }\end{array}$ \\
\hline & & $\begin{array}{l}\text { Pembuatan standarisasi arsitektur TI } \\
\text { menggunakan enterprise architecture }\end{array}$ \\
\hline & & $\begin{array}{l}\text { Pembangunan arsitektur integrasi dan } \\
\text { platform sistem informasi }\end{array}$ \\
\hline & \multirow[t]{2}{*}{$\begin{array}{l}\text { 5. pengoptimalan terhadap aset, } \\
\text { sumber daya, dan kapabilitas TI }\end{array}$} & $\begin{array}{l}\text { Pengembangan sistem informasi yang } \\
\text { memadai antar unit dan saling terintegrasi } \\
\text { (sehingga proses bisnis lebih efisien, efektif, } \\
\text { dan produktif, bahkan dapat memperoleh } \\
\text { keunggulan kompetitif, tanpa harus } \\
\text { menurunkan kualitas produk/jasa dan } \\
\text { layanan customer.) }\end{array}$ \\
\hline & & $\begin{array}{l}\text { Pengembangan sistem informasi untuk } \\
\text { pengelolaan penelitian dan pengembangan } \\
\text { ilmu baik untuk dosen dan mahasiswa }\end{array}$ \\
\hline \multirow{3}{*}{$\begin{array}{l}\text { Perspektif } \\
\text { Orientasi Masa } \\
\text { Depan (Future / } \\
\text { Innovation). }\end{array}$} & $\begin{array}{l}\text { 1. Meningkatkan kapasitas dan } \\
\text { kapabilitas tenaga IT }\end{array}$ & $\begin{array}{l}\text { Jumlah pelatihan/pengembangan } \\
\text { kompetensi yang diikuti oleh karyawan }\end{array}$ \\
\hline & $\begin{array}{l}\text { 2. Tersedianya knowledge, keahlian, } \\
\text { dan inisiatif untuk inovasi IT untuk } \\
\text { mendukung kegiatan IT }\end{array}$ & $\begin{array}{l}\text { Pembuatan perencanaan terkait IT pada unit } \\
\text { IT Support }\end{array}$ \\
\hline & 3. Optimasi penggunaan IT & $\begin{array}{l}\text { Pelaksanaan sosialisasi sistem yang telah di } \\
\text { rancang oleh unit IT Support }\end{array}$ \\
\hline
\end{tabular}

\section{KESIMPULAN}

Dari hasil penelitian yang dilakukan dalam perancangan IT Balanced Scorecard, didapatkan kesimpulan bahwa data dari hasil pengukuran yang telah ada sebelumnya, terkait dengan kinerja TI belum menunjukkan adanya sebuah pengukuran dan strategi TI yang matang. Ini dilihat dari ada 2 indikator utama dari kinerja IT yaitu, Pengembangan Sistem Informasi dan Support Dashboard YPT. Hasil pengukuran kinerja Pengembangan Sistem informasi menunjukkan angka ketercapaian kurang dari 100 persen, dan angka ketercapaian Support Dashboard YPT menunjukkan angka 100\%. Hal tersebut belum mencerminkan adanya sebuah strategi TI untuk mendukung strategi bisnis secara keseluruhan. Sehingga dibutuhkan IT Balanced Scorecard untuk menggambarkan strategy maps dan ukuran-ukuran penting strategi IT. Proses hasil penerjemahan strategi dari visi misi institusi menghasilkan 12 sasaran strategis dan menghasilkan 20 KPI yang akan digunakan sebagai ukuran kinerja IT Balanced Scorecard yang dapat dilihat pada Tabel 4. Hasil sasaran strategis dibentuk ke dalam sebuah strategy maps agar terlihat gambaran "as-is condition" institusi ke depannya, yang dapat dilihat pada Gambar 5. 


\section{Wahyu Adi Prabowo1*, Yudha Saintika2}

Perancangan IT Balanced Scorecard dalam Penyusunan Strategy maps Perguruan Tinggi (Studi kasus: Institut Teknologi Telkom Purwokerto)

\section{DAFTAR PUSTAKA}

Brynjolfsson E. 1994. The productivity paradox of information technology: Review and assessment. Center for Coordination Science, MIT Sloan School of Management, Cambridge, Massachusetts.

Brynjolfsson E, Lorin M \& Hitt. 1998. Beyond the productivity paradox: Computers are the catalyst for bigger changes, Forthcoming in the Communications of the ACM.

Chircu, Alina, M., Kauffman, J. Robert \& Keskey, Doug. 2001. Maximizing the value of internet-based corporate travel reservation systems. Communications of the ACM, November, V44, I11, pp-57- 63.

Herdiansyah, Kunang, Akbar. 2014, IT Strategy Alignment in University Using IT Balanced Scorecard Framework, Article in Advanced Science Letters , DOI: 10.1166/asl.2014.5685 Adv. Sci. Lett. 20, 2038-2041.

Indrawan, R. 2008. Penyelenggaraan Tridharma Perguruan Tinggi Secara Produktif, Terukur, Berkelanjutan, dan Akuntabel Dalam Kaitannya Dengan Membentuk Lulusan Yang Cerdas dan Kompetitif. Jabar \& Banten. Retrieved from https://rullyindrawan.files.wordpress.co $\mathrm{m} / 2013 / 02$ /paradigma-perguruantinggi.pdf

IT Governance Institute (ITGI), ISACA. 2005. measuring and demonstrating value of IT.
IT Telkom Purwokerto. 2018, Struktur Organisasi. Retrieved from http://ittelkom-pwt.ac.id/aboutus/organisasi/

Lee, A. H. I., Chen, W., \& Chang, C. 2008. A fuzzy AHP and BSC approach for evaluating performance of IT department in the manufacturing industry in Taiwan. https://doi.org/10.1016/j.eswa.2006.08. 022

Maria. 2011, Perbandingan Sistem Informasi Akademik Universitas Kristen Satya Wacana Menggunakan COBIT Framework, Journal of Eonomic Foccus, vol 10, no. 2 hal 140-149. ISSN 1412-3851.

Mason G., Wagner K., Finegold D., \& Keltner B. 2000. The "IT Productivity Paradox" Revisited: International Comparisons of Information Technology, Work Organisation and Productivity in Service Industries, Vierteljahrshefte zur Wirtschaftsforschung 69. Jahrgang, Heft 4/2000, S. 618-629.

Ristekdikti. 2014. Good University Governance (GUG). Retrieved from https://luk.staff.ugm.ac.id/atur/statuta/l atih/2014/03GoodUniversityGovernance. pdf

Unit Sisfo. 2015, ST3 Telkom Purwokerto Information Technology Blue Print. 